\title{
The Pluralistic Integration of Concept, Layout, Pattern and Mechanism the Exploration and Practice of Economic and Management Degree Graduate Education
}

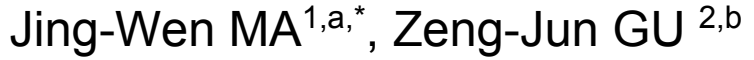 \\ ${ }^{12}$ Shandong Technology and Business University, Yantai Shandong, China, 264005 \\ axssy163@163.com, bjessie1128@163.com
}

\begin{abstract}
Keywords: Economics and Management; Professional Degree Graduate Student; Graduate Education
\end{abstract}

\begin{abstract}
In order to better promote the rapid development of economic management class professional degree education, we explored the idea of Economic Management Training professional degree graduate education, planning a degree education strategic layout. Then we constructed Postgraduate Education modes, including "modular" system and content, "integrated" teaching methods, "pyramid" design quality, "Working and Learning Alternation" training course, "real and simulated integration" practice platform, etc. We have improved the professional degree graduate management mechanisms, including "flat" organizational design, "the whole process of dynamic management" mechanism "Comprehensive + Order" enrollment structure, Cooperative mode design, "diversity" teaching team, "all aspect orientation "quality control system, etc. So as to improve the education quality provided a guarantee.

With the development of railway transportation, especially the rapid development of railway construction, relevant industries need large quantities of the inter-disciplinary talent of management and technology. Beijing Jiaotong University, as the industry characteristics of colleges and universities, has accumulated more than hundred years in the field of transportation. Over the years, she is shouldering the important task of training talents for railway industry, services, and railway. Under such a background, Beijing Jiaotong university school of economy and management (hereinafter referred to as school of management ) in a professional degree education, and communities in professional degree program for the overall strategic layout, constantly optimize the structure, enhance the school's core competitiveness, in the long-term practice, gradually forms a distinctive mode of professional degree education, is dedicated to the social culture have both management and technology of interdisciplinary talents with high quality.
\end{abstract}

\section{Graduate Education in Professional Degree of Administration Strategy Layout}

School of economy and management has applied economics, business administration, management science and engineering, safety technology and engineering (build) and statistics (build), and other five first-level discipline doctoral degree, more than 20 doctoral degree program, 7 first-level discipline master degree, 14 professional degree graduate admissions program. In such a vast amount of discipline system, after much argument and discussion, adhering to such principles as highlighting the advantage project, optimizing the structure of categories, equipping with as a whole resources, school of economy and management does the overall strategic layout for professional degree program, and integrates education resources, forms the differentiation, diverse category structure, starting from the long-term sustainable development.

\section{On the Basis of the Discipline Advantage and Industry Background, Ensure the Characteristic Development of Key Projects}

Relying on these two disciplines advantage of the enterprise management, management science and engineer in Beijing, given the great progress in the railway industry, investment and financing, capital operation demand background, school of economy and management focuses on developing such five characteristic, key projects as the MPACC, MBA, EMBA, project management, master of 
engineering in engineering and logistics areas and the development of the IMBA program, MPA, master of international business and master of applied statistics, auditing, master, master of accounting, assets evaluation master, master of industrial engineering, safety engineering master's nine auxiliary projects, so that reaching 14the professional degree graduate admissions project.

\section{On the Basis of Long-Term Development School of Economy and Management Forms the Classified Structure of Differentiation}

In recent years, with the enlarging of graduates and the changing of social needs, demand of talents with innovation, entrepreneurship and practice ability of high-level has become more and more urgent. And countries also gradually will convert graduate student education mainly from academic to practical. Under this background, the school of economy and management adjusts the structure of graduate student category, combines with the graduate student education, which is based on industry and discipline of strategic layout, and formulates reasonable configuration of strategic layout of two types of professional degree graduate education projects which includes the full-time and part-time training. In terms of student resource, there are two types of students: recent graduates and students with practical experience; and in terms of degree-conferring, there are two types: two certificates (degree certificate and diploma) and one certificate (degree certificate) projects, so as to maintain long-term sustainable development, and to build the core competitiveness as the goal.

\section{The Integration of Education Resources to Build a Diversified Training Structure}

Under the condition of the coexistence of a variety of professional degree programs, the contradiction between the limited education resources and training quality is very obvious. In order to reasonably allocate resources and guarantee the development of key projects radiate other projects development, school of economy and management classifies the aspects of training mode, to integrate the utilization of resources, making it play a bigger role. For example, in teaching mode, there are many different modes: the school full-time regular learning, period of time of learning in the year, learning in the enterprises, weekends learning, forming the net structure of "point, line, face, solving the problem of limited resources. At the same time, in the way of tutor and teaching arrangement, school of economy and management gives full consideration to the student and teacher's specialty and interest. According to the requirements of different project teaching time, school breaks the disciplinary boundaries in large scope and project boundaries, maximizing the teacher resources of reasonable application.

\section{Training Mode of the Specialized Degree Graduate Student}

With the idea of "based on the industry, highlighting advantage, with guidance of demand, unity of knowledge and practice" and with the goal of cultivating high quality talents both management and technology for society, school of economy and management constructs professional degree graduate education system under the background of the economic management, as shown in figure 1.

\section{"Modular" Course System and Content with New Features}

Adhering to market-oriented and employment guidance, according to market needs, the courses are set up, the curriculum and teaching plan are determined flexibly. In the way of the course feature localization, advantage disciplines is prominent, on the analysis of the duties, tasks, knowledge and ability, the modular curriculum knowledge structure system is designed. The knowledge of the course content is decomposed into several modules, each module with a relatively independent and complete unit. Course modules focuses on practicality and pertinence, and pays attention to practical and forward-looking organic link. Each module with basic theory, case study and simulation and seminar, through the study of the three progressive parts, knowledge level is improved. 


\section{"Integrated" Teaching Methods, Improve the Quality of Classroom Teaching}

To widen students' view, increase the knowledge frontier, highlight the curriculum integration and decision-making guidance, and emphasize the close ties with the reality and face the international competition environment, school takes "five Yuan" type teaching mode of the multimedia teaching, interactive teaching, case teaching, practice teaching and teaching with BBS ,blends the modern technology and management scenarios into the order of teaching, and fully blend in management practice and theory together, the basic theory and practical case, policy and practice at home and abroad, connectivity of cutting-edge knowledge, blend in management practice and system construction. By "integrated" teaching methods, the students' understanding of management theory is fully enhanced to improve their practical skills.

\section{"Pyramid" Type Structure Design, Improving Practice and Analysis Ability}

In the construction of teaching content and knowledge system, it should not be limited to a particular subject. The most widely used the latest technological achievements in the production and management experience is included in the curriculum, the establishing a pyramid system knowledge and ability structure, and strengthening the cultivation of the students' practical and analytic skills. The students' skill is improved, based on the basic quality education, strengthening the base layer to management theory. the basic theory teaching and general management theory courses); Specific management theory and application oriented completes the middle tier (enterprise specific management theory and professional core courses); With innovation, entrepreneurial ability training as a fundamental, in order to compound, extraversion and analytical ability education as the important form at the top (sand table simulation, empirical analysis and the application type, management reports, such as entrepreneurship courses), in the structure of the pyramid.

\section{Cultivation Mode of "Alternation of Work and Study", Enhance The Combination of Production, Study and Research.}

Extending the professional degree education into the enterprise to realize the cultivation of "alternation of work and study" mode. In the aspect of teaching, on the one hand, the problem of the enterprise is brought into the campus, and the problem of enterprises is taken as a thesis topic, thus, the enterprise problems of practical difficulties and cultivate high-level talents, are to be solved ; On the other hand, the school education and the content of practice teaching is enriched, and the level of school research is enhanced and the implementation of double tutorial system of school and enterprise enriches the faculty; Finally, students' study and research ability is improved, and at the same time, the applicability of the talent training is forward, playing the enthusiasm of students, businesses, schools, achieving win-win and mutual benefit. 


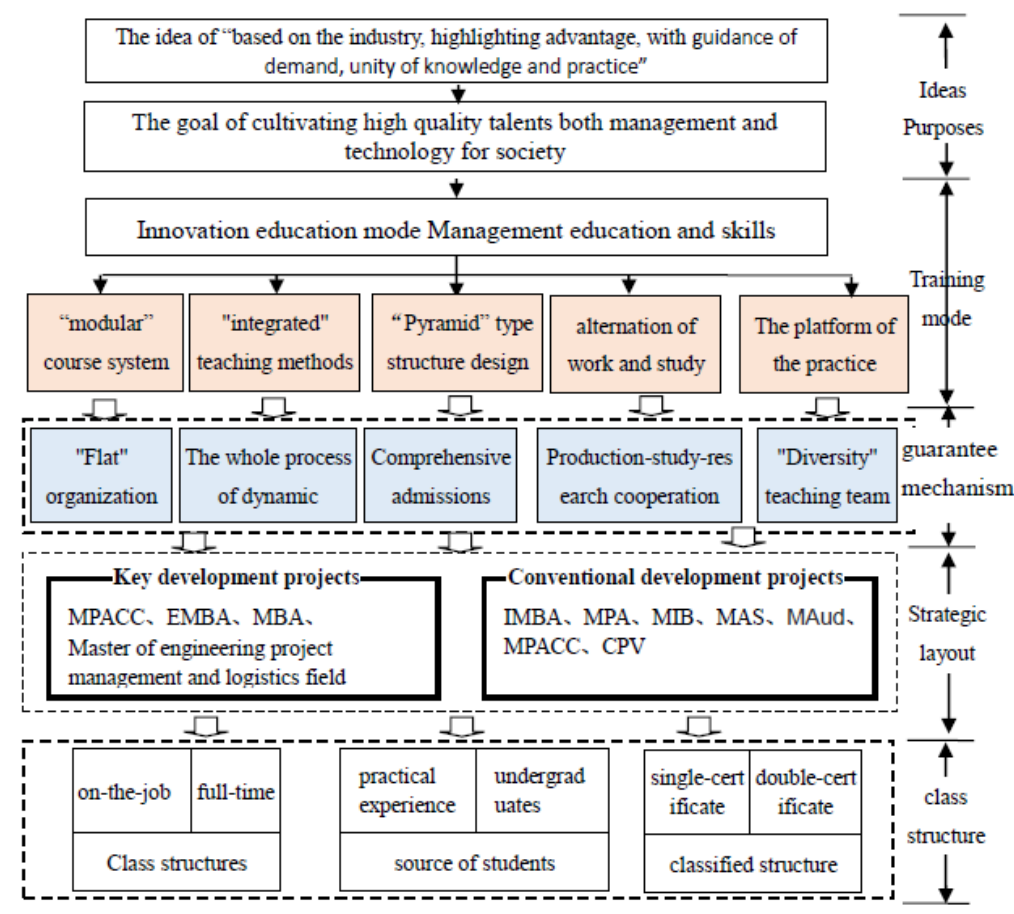

Figure 1 The system design of graduate education in professional degree of administration

\section{The Platform of the Practice Combined with Simulation, Promoting Students' Practical Ability}

According to the principle of "Technology with front, platform comes from practice, based on the functional equivalent scene", through the production and enterprise a campus complementary practice teaching platform is jointly set up. In the process of teaching practice, school attempts to adopt the way of virtual enterprise. "simulation training company" makes 7 to 15 people as a team, playing real role, fully running in accordance with the normal operations, causing the student to complete the industry as a whole cognition, operating practice, ability training and innovative practice, and forming a high-quality resources integration and synergy, university-enterprise joint training for teaching and scientific research of new experiment teaching model. At the same time, in order to further understand the needs of enterprises, enhance the students' practical ability, and improve students' employment competitive power, school establishes a practice base for students to participate in the off-campus internship and social practice in a number of large enterprises, and makes the institutionalization of the construction of practice base.

\section{Guarantee Mechanism of Graduate Education in Professional Degree of Administration \\ "Flat" Organization Design to Realize Management Flexibility}

School established in January 2008 the professional degree education center, including MBA, EMBA, MPACC center, engineering center and international ERP and IMBA program, MPA center, professional degree education center and EDP center office. To mobilize the enthusiasm of each center staff, school establishes and improves the center work target responsibility system and the incentive mechanism, walking out of the road of a "projectization operation and carreerization propulsion, and brandization development".

The Whole Process of Dynamic Management Mechanism to Realize Students' Career Management

From analysis of social and enterprise needs as a starting point, school makes clear specific characteristics of professional degree education students, combines the feature of students with 
adjustment of training target, and refines the training scheme, aiming at the professional degree education in a new environment. Under the condition such as quality, time, cost constraints, with that different types of targets of enterprises and institutions to cultivate qualified talents for management practices, school takes each professional degree as a project, and have the dynamic management of students career in accordance with the "start, plan, implement and control - ending" the whole process of implementation of the whole process.

\section{“Comprehensive + Orders” Admissions Structure to Improve Students Quality}

In the students recruitment, school makes strict quality management, pays attention to the cooperation with enterprise group, takes the way of order admissions. These measures will meet the demand of enterprise actual implement. In order to improve training quality, in the structure of students, school adapts to the need of the industry, provides more flexible quality education services according to the actual needs of students, maximizing the project's own characteristics. At the same time, school also has realized the learning structure which gives priority to full-time study. School banned part-time MBA programs, all full-time instead, and master of engineering must take a full-time for group class way of learning.

\section{Production-Study-Research Cooperation Pattern Design, Following the Enterprise Actual Demand}

In teaching management, school strengthens the professional degree graduate education mode innovation research, especially the innovation of teaching management mode for full-time study. The research focuses on how to carry out and improve the students' innovation and entrepreneurship practice ability. For promoting production-study-research cooperation, and gradually establishing a duality academic organization pattern, i.e. the traditional teaching, scientific research and the stability of the administrative organization and pioneering academic organization engaged in the scientific and technological innovation synergy. In addition, the college has formed a characteristic "group class" education mode, gearing to the needs of a specific enterprise, "order form training" will meet enterprise actual demand.

\section{"Diversity" Teaching Team is the Strong Teaching Staff guarantee}

To ensure quality of talent cultivation, and adapt diverse training goal, the school has realized the diversity of internal teaching staff in colleges and universities, such as academic, research, practice, structure, general type, complex, and management staff. The introduction channel of talent is diversified, encouraging interdisciplinary, and applies a system of principal under the mechanism of course construction of teachers team. Heads of the each course design course content, and carry out the teaching team. In addition, the school invited some enterprise relevant personnel as a graduate student mentor or part-time tutor, which means double tutorial system, and obtained a certain result, welcomed the students.

\section{Comprehensive Quality Control System, Improving Training Quality}

To ensure quality of graduate education in professional degree, the school set up quality guarantee system including admissions, the teaching quality monitoring, dissertation quality control and so on. At the same time,3 quality monitor system of the professional degree leading group review mechanism, the academic committee monitoring mechanism and students' supervision and feedback mechanism are also included. In addition, in order to evaluate the effect of professional degree graduate education, the government, society, the third party are taken as the center of the institute of external evaluation system and build the hierarchical, multi-angle comprehensive three-dimensional education quality evaluation system by combining their own internal evaluation system. 


\section{Conclusion}

With the development of rail transit business, especially the demand of the rapid development of railway construction, school of management actively adjust the professional degree training concept in a professional degree graduate education as the gripper, based on accumulated more than hundred years in the transportation field profound academic accumulation, features a service enterprise, pay attention to the development of theory of carding and application ability, improve the professional degree postgraduate training pattern and management mechanism, make the students constantly optimized structure, improve training quality significantly, social influence and brand awareness rising, in schools, nationwide made good demonstration effect.

\section{Acknowledgements}

Fund project: The research project on teaching reform of shandong undergraduate college in 2016 ("Integration of concept, path, mechanism and system: the research on quality assurance of application-oriented undergraduate accounting talents ")

\section{Reference}

[1]Jianguo Huang. Exploration and practice of full-time professional degree graduate student training, take Nanjing University of finance and economics as an example Academic degrees and graduate education, 2013, (3):20-22.

[2]Jingjuan Guo. Innovation and practice of Master of engineering education mechanism and training mode [J].Project management technology, 2009, 7(5):72-76.

[3]Wenfeng Wang, Wenting Guo. Diversified development of higher education and innovative personnel training, based on the perspective of biodiversity [J]. Journal of Kunming University of Science and Technology (Social Sciences), 2013, 13 (1):99-103.

[4]Guiting Fang. According to the needs of society, promote the reform of postgraduate training mode----take Wuhan University as an example [J]. Journal of Hubei Normal University (Philosophy and Social Science), 2009, 29(01):122-124.

[5]Xueyi Zhu. On research capacity of the academic master's top creative talents cultivation [J]. Journal of Graduate Education, 2012(04):50-53.

[6]Zhibo Ge. Thinking on the graduate student course management [J].Heilongjiang higher education, 2002(020:83-85.

[7]Guanhua Wen, Wenzhong Jiang, Hongliang Chen etc. Pay special attention to the professional practice in order to ensure the quality of full-time graduate education in professional degree. [J]. Academic degrees and graduate education, 2010, (8):1-4.

[8Xuezhen Tian, Jun Zhang. Full-time professional degree graduate education quality - based on the exploration of "four spiral" training mode [J]. Journal of Graduate Education, 2013, (3):82-86.

[9]Dongmei Zheng. Combination of exploration full-time professional degree postgraduate training mode [J]. Chinese University Technology Transfer, 2009, (6):46-47. 